\title{
REVIEW
}

Open Access

\section{Short-term outcomes of on- vs off-pump coronary artery bypass grafting in patients with left ventricular dysfunction: a systematic review and meta-analysis}

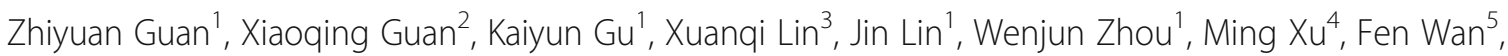
Zhe Zhang ${ }^{1 *}$ and Chunli Song ${ }^{6^{*}}$

\begin{abstract}
Objectives: Does the manipulation of the off-pump CABG (OPCAB) in patient with depressed left ventricular function is better than on-pump CABG (ONCAB) approach in in-hospital mortality and morbidities? Here we undertook a meta-analysis of the best evidence available on the comparison of primary and second clinical outcomes of the off-pump and on-pump CABG.
\end{abstract}

Design: Systematic literature reviewer and meta-analysis.

Data sources: PubMed, EMBASE, Web of science and Cochrane Center Registry of Controlled Trials were searched the studies which comparing the use of the off-pump CABG(OPCAB) and on-pump CABG (ONCAB) for patients with LVD during January 1990.1 to January 2018.

Eligibility criteria: All observation studies and randomized controlled trials comparing on-pump and off-pump as main technique for multi-vessel coronary artery disease (defined as severe stenosis (>70\%) in at least 2 major diseased coronary arteries) with left ventricular dysfunction(defined as ejection fraction (EF) $40 \%$ or less) were included.

Data extraction and synthesis: Authors will screen and select the studies extract the following data, first author, year of publication, trial characters, study design, inclusion and exclusion criteria, graft type, clinical outcome, assess the risk of bias and heterogeneity. Study-specific estimates will pool through the modification of the NewcastleOttawa scale for the quality of study and while leave-one-out analysis will be used to detect the impact of individual studies on the robustness of outcomes.

* Correspondence: Zhangzhe@bjmu.edu.cn; schl@bjmu.edu.cn

'Department of Cardiology surgery, Peking University Third Hospital, 49 North Garden Rd., Haidian District, Beijing 100191, China

${ }^{6}$ Department of Orthopedics, Peking University Third Hospital, 49 North Garden Rd., Haidian District, Beijing 100191, China

Full list of author information is available at the end of the article

(c) The Author(s). 2020 Open Access This article is licensed under a Creative Commons Attribution 4.0 International License, which permits use, sharing, adaptation, distribution and reproduction in any medium or format, as long as you give appropriate credit to the original author(s) and the source, provide a link to the Creative Commons licence, and indicate if changes were made. The images or other third party material in this article are included in the article's Creative Commons licence, unless indicated otherwise in a credit line to the material. If material is not included in the article's Creative Commons licence and your intended use is not permitted by statutory regulation or exceeds the permitted use, you will need to obtain permission directly from the copyright holder. To view a copy of this licence, visit http://creativecommons.org/licenses/by/4.0/ The Creative Commons Public Domain Dedication waiver (http://creativecommons.org/publicdomain/zero/1.0/) applies to the data made available in this article, unless otherwise stated in a credit line to the data. 


\begin{abstract}
(Continued from previous page)
Results: Among the 987 screened articles, a total of 16 studies (32,354 patients) were included. A significant relationship between patient risk profile and benefits from OPCAB was found in terms of the 30-day mortality (odds ratio $[\mathrm{OR}], 0.84 ; 95 \%$ confidence interval $[\mathrm{Cl}], 0.73-0.97 ; P=0.02)$, stroke $(\mathrm{OR}, 0.69 ; 95 \% \mathrm{Cl}, 0.55-0.86 ; P=0.00)$, myocardial infarction $(\mathrm{MI})(\mathrm{OR}, 0.71 ; 95 \% \mathrm{Cl}, 0.53-0.96 ; P=0.02)$, renal failure $(\mathrm{OR}, 0.71 ; 95 \% \mathrm{Cl}, 0.55-0.93 ; P=0.01)$, pulmonary complication $(\mathrm{OR}, 0.68 ; 95 \% \mathrm{Cl}, 0.52-0.90 ; P=0.01)$, infection $(\mathrm{OR}, 0.67 ; 95 \% \mathrm{Cl}, 0.49-0.91 ; P=0.00)$, postoperative transfusion $(\mathrm{OR}, 0.25 ; 95 \% \mathrm{Cl}, 0.08-0.84 ; P=0.02)$ and reoperation for bleeding $(\mathrm{OR}, 0.56 ; 95 \% \mathrm{Cl}, 0.41-$ $0.75 ; P=0.00)$. There was no significant difference in atrial fibrillation (AF) $(\mathrm{OR}, 0.96 ; 95 \% ; \mathrm{Cl}, 0.78-1.41 ; P=0.56)$ and neurological dysfunction (OR, 0.88; 95\% Cl, 0.49-1.57; $P=0.65)$.

Conclusions: Compared with the on-pump CABG with LVD, using the off-pump CABG is a better choice for patients with lower mortality, stroke, MI, RF, pulmonary complication, infection, postoperative transfusion and reoperation for bleeding. Further randomized studies are warranted to corroborate these observational data.
\end{abstract}

Keywords: On-pump, Off-pump, Left ventricular dysfunction, Coronary artery bypass grafting

\section{Introduction}

The impresses left ventricular function is important risk factors to effect the clinical outcome of coronary artery bypass surgery. Several meta-analysis has been performed that investigated the short-term and long-term clinical prognosis of on-pump versus off-pump CABG $[1,2]$. Topkara et.al found that in-hospital mortality and morbidities were significantly higher in patients underwent CABG with depressed LV function than normal LV function [3]. For patient with lower left ventricular function, comparing medical therapy with CABG for patients with symptomatic coronary artery disease and ejection fraction (EF) as low as $30 \%$ have shown a longterm survival benefit for those receiving CABG [4].

The CABG focus on long term benefits compared with medical treatment of coronary artery disease in patients with lower left ventricular function [5] and up to $15 \%$ of patients present with severely depressed left ventricular function [6] .Due to the improved technique and LVAD/ECMO led to progressively improved CABG clinical outcome in recent years. on the other hand, it has been suggested that off-pump CABG may be beneficial in patients with severely depressed LV function by avoiding prolonged ischemic times. In the 2011, Jarrel OA et.al [7] has been aggregated meta-analysis which has focused on the comparison of clinical results of the CABG, especially in patients with LVD show that offpump CABG may be associated with lower incidence of early mortality in patient with LVD. Therefore, the advantages of off-pump compared with conventional onpump CABG in patients with LVD remain a source of controversy. On this background, the aim of this systematic review was to synthesize the results from all studies reporting the short-term clinical outcome that investigated on- versus off-pump CABG in patients with LVD.

\section{Methods}

This systematic review and meta-analysis follow the preferred reporting items for systematic reviews and metaanalysis statement.

\section{Search strategy and definition}

A medical librarian developed searches to identify studies that compared the clinical outcome between onpump and off-pump CABG. PubMed, EMBASE, Web of science and Cochrane Center Registry of Controlled Trials were searched during January 1990.1 to January 2018. Searches used subject headings and keywords for the following terms: 'coronary artery bypass, off-pump, on-pump, left ventricular dysfunction, cardiopulmonary bypass, CABG.'(Supplement 1 search strategy).

To be eligible for inclusion in our meta-analysis, trials had to conform to the following criteria: the observation studies comparing on-pump and off-pump as main technique for multivessel coronary artery disease (defined as severe stenosis $(>70 \%)$ in at least 2 major diseased coronary arteries) with left ventricular dysfunction(defined as ejection fraction $40 \%$ or less). Animal studies, review papers were excluded. Studies that did not have any of the desired outcome measures or participants who were treated by other modalities such as percutaneous coronary intervention and emergency or salvage conditions were excluded. Incomplete data were excluded. Studies that included interventions other than off-pump versus on-pump CABG were excluded.

\section{Data extractions and quality assessment}

Three reviewers (Guan; Gu; Lin) independently extracted the following data from each study, first author, year of publication, trial characteristics, study design, inclusion and exclusion criteria, graft type, clinical outcome (Fig. 1). The following variables were included: 


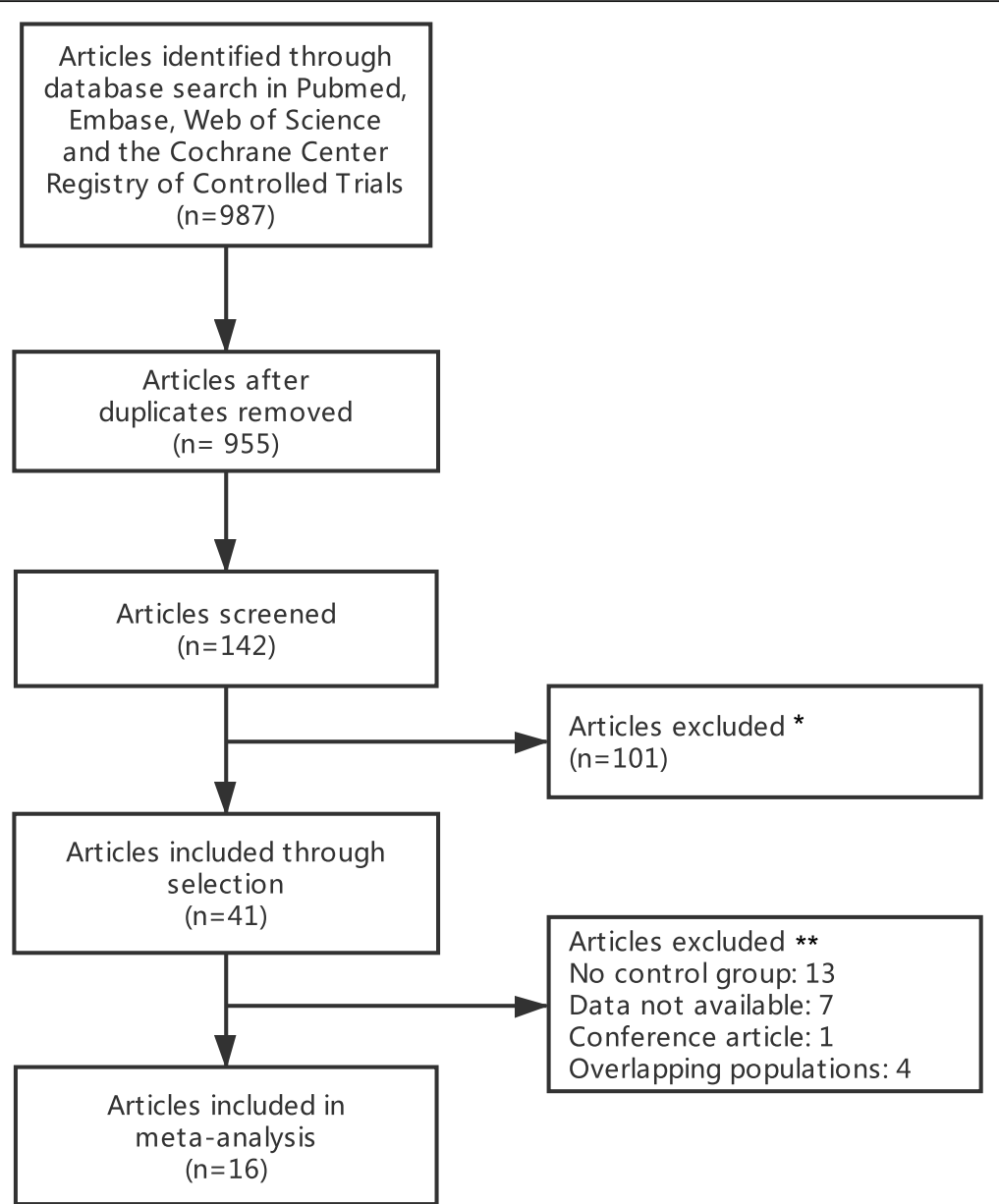

Fig. 1 Preferred reporting items for systematic reviews and meta-analysis flow diagram

study demographics (sample size, publication year, design, and country), patient demographics and comorbidities (age, sex, diabetes, ejection fraction, chronic obstructive pulmonary disease). In the first screening phase, we have excluded 101 papers due to they were irrelevant. The modification of the Newcastle-Ottawa scale is carried out in our meta-analysis with a quality assessment score. The modified Newcastle-Ottawa scale checklist has been summarized in Table 1, and we also define the studies scores higher than 6 as the highquality study. The quality of all studies has been evaluated by two independent researchers (Zhou; Lin).

\section{Outcomes}

The primary clinical endpoint was 30-days mortality. The secondly clinical endpoint was stroke, myocardial infarction and renal failure, atrial fibrillation, renal failure, pulmonary complications, postoperative transfusion, neurological dysfunction and infection. Pulmonary complications were include respiratory failure (pulmonary insufficiency requiring intubation and ventilation for a period of $72 \mathrm{~h}$ or more at any time during the postoperative stay) and postoperative pneumonia (positive sputum cultures with subsequent antibiotic treatment, or an infiltrate on postoperative chest $x$-ray diagnosed as pneumonia or pneumonitis). The period of secondly clinical outcome were defined as 30 days after surgery.

\section{Statistical analysis}

The relationship between on-pump and off-pump CABG and clinical outcome was compared directly by pooling data from the included studies using "meta" and "metaphor" packages in R (version 3.5.3, R Project; R Foundation for Statistical Computing, Vienna, Austria) [8]. We pooled the clinical outcome using OR with $95 \%$ CI. OR were used as the common measure for dichotomous data follow by the previous study [7] and Cochrane Handbook for Systematic Reviews of Intervention [9]. The random-effects model because variation among studies due to patients undergoing operations in different centers have varying risk profiles and selection criteria for each surgical technique. We evaluated the heterogeneity by focusing on patients with LVD and a 
Table 1 Quality assessment of included studies using Newcastle-Ottawa scale

\begin{tabular}{|c|c|c|c|c|c|c|c|c|c|c|c|}
\hline \multirow[t]{2}{*}{ First author } & \multirow[t]{2}{*}{ Year } & \multicolumn{4}{|c|}{$\underline{\text { Selcetion }}$} & \multicolumn{2}{|c|}{ Comparability } & \multicolumn{3}{|c|}{ Outcome } & \multirow[t]{2}{*}{ Tota } \\
\hline & & S1 & S2 & S3 & $\$ 4$ & $\mathrm{C} 1$ & $\mathrm{C} 2$ & $\mathrm{O} 1$ & $\mathrm{O} 2$ & $\mathrm{O} 3$ & \\
\hline Arom, K.V. & 2000 & 1 & 1 & 0 & 1 & 1 & 0 & 1 & 1 & 1 & 7 \\
\hline Yokoyama, T. & 2000 & 1 & 1 & 0 & 1 & 1 & 0 & 1 & 1 & 1 & 7 \\
\hline Shennib, H. & 2002 & 1 & 1 & 0 & 1 & 1 & 0 & 1 & 1 & 1 & 7 \\
\hline Al-Ruzzeh, S. & 2003 & 1 & 1 & 0 & 1 & 1 & 0 & 1 & 1 & 1 & 7 \\
\hline Ascione, R. & 2003 & 1 & 1 & 0 & 1 & 1 & 1 & 1 & 1 & 1 & 8 \\
\hline Goldstein, D.J. & 2003 & 1 & 1 & 0 & 1 & 1 & 1 & 1 & 1 & 1 & 7 \\
\hline Darwazah, A.K. & 2006 & 1 & 1 & 0 & 1 & 1 & 1 & 1 & 1 & 1 & 8 \\
\hline Sharoni, E. & 2006 & 1 & 1 & 0 & 1 & 1 & 0 & 1 & 1 & 1 & 7 \\
\hline Filsoufi, F. & 2007 & 1 & 1 & 1 & 1 & 1 & 0 & 1 & 1 & 1 & 8 \\
\hline Youn, Y.N. & 2007 & 1 & 1 & 0 & 1 & 1 & 0 & 1 & 1 & 1 & 7 \\
\hline Qiu, Z.B. & 2008 & 1 & 1 & 0 & 1 & 1 & 0 & 1 & 1 & 1 & 8 \\
\hline Attaran, S. & 2010 & 1 & 1 & 0 & 1 & 1 & 0 & 1 & 1 & 1 & 7 \\
\hline Caputti, G.M. & 2011 & 1 & 1 & 0 & 1 & 1 & 0 & 1 & 1 & 1 & 7 \\
\hline Emmert, M.Y., & 2012 & 1 & 1 & 0 & 1 & 1 & 0 & 1 & 1 & 1 & 7 \\
\hline Keeling, W.B. & 2013 & 1 & 1 & 0 & 1 & 1 & 0 & 1 & 1 & 1 & 7 \\
\hline Ueki, C. & 2016 & 1 & 1 & 0 & 1 & 1 & 0 & 1 & 1 & 1 & 7 \\
\hline
\end{tabular}

S1: Representativeness of the exposed cohort; S2: Selection of the non-exposed cohort, S3: Ascertainment of exposure, S4: Demonstration that outcome of interest was not present at start of study; C1\&2: Comparability of cohorts on the basis of the design or analysis; O1: Assessment of outcome, O2: Was follow-up long enough for outcomes to occur, O3: Adequacy of follow-up of cohorts

quality score greater than 7 and Heterogeneity was reported as low $\left(\mathrm{I}^{2}=0-25 \%\right)$, moderate $\left(\mathrm{I}^{2}=26-50 \%\right)$, high $\left(\mathrm{I}^{2}>50 \%\right)$, consistent with guidelines. Publication bias was assessed visually by funnel plot and quantitatively by the Egger test [10]. We calculated pooled ORs using the Mantel-Haenszel method. A leave-one-out analysis was performed to examine the impact of individual studies on the robustness of the primary and secondary outcomes. Statistical significance was assumed for $P<0.05$.

\section{Results}

Among the 987 screened articles, article excluded due to screened the title(29 studies),abstract(60 studies),key word(12 studies) at first time and full text(25 studies) at second time. a total of 16 studies(32,354 patients; 24,295 case of on-pump CABG and 8269 cases of off-pump CABG)were included (Table 2).

Six of the studies were multicenter. Five studies formed the USA, three from UK and two from Israel, and one each from Canada, Korea, Brazil, China, Switzerland and Japan. All observational studies included were of high quality and low risk of bias. The number of patients in the individual studies ranged from 26 to 20 , 509 patients in the on-pump CABG group and from 31 to 5158 in the off-pump CABG group. The overall mean age ranged from 65.62 years in the on-pump CABG group and 64.23 in the off-pump CABG group. In the off pump group, the overall percentage of female varied from $12.9-38 \%$, whilst in the on pump group the percentage of female ranged from 8 to $36.3 \%$. All patients had low-normal ejection fraction (range from $\leq 20 \%$ to $\leq 35 \%$ ).

For short-term outcomes, mortality was reported in 15 studies (31,668 patients) [11-21] and pulmonary complication in 9 studies (3987patients) [11, 12, 15, 16, 19, 20, 22, 23], renal failure in 15 studies ( 31,801 patients) [5, 11-18, 20-22, 24], infection in 8 studies (5037 studies) $[5,11,12,14,15,20,25]$, AF in 12 studies $(30,789$ patients) $[12,14-20,22-25]$, postoperative transfusion in 4 studies (2565 patients) [20,21, 24, 25], reoperation for bleeding in 11 studies(5418 patients) $[5,11,13,14,16$, $20,21,23,24]$, MI in 13 studies (31,686 patients) [5, 11$20,22,23,25]$ and neurological dysfunction in 7 studies (1536 patients) [12, 14-20, 22, 23, 25].

\section{Primary outcomes}

30-day mortality was $3.34 \%$ in off-pump group versus $3.53 \%$ in on-pump group (OR, 0.84; 95\%CI, 0.73-0.97; $P=0.02)$ and Leave-one-out analysis supported the robustness of this finding(Figure 2). Funnel plot showed no publication bias (Egger test intercept was - 1.53-0.12, $P=0.12$,Supplementary Figure 1a). However, when excluding the study of Ueki, C. et.al, the off-pump was no longer associated with a significantly lower risk of 30day mortality. (Supplementary Figure 1b). 


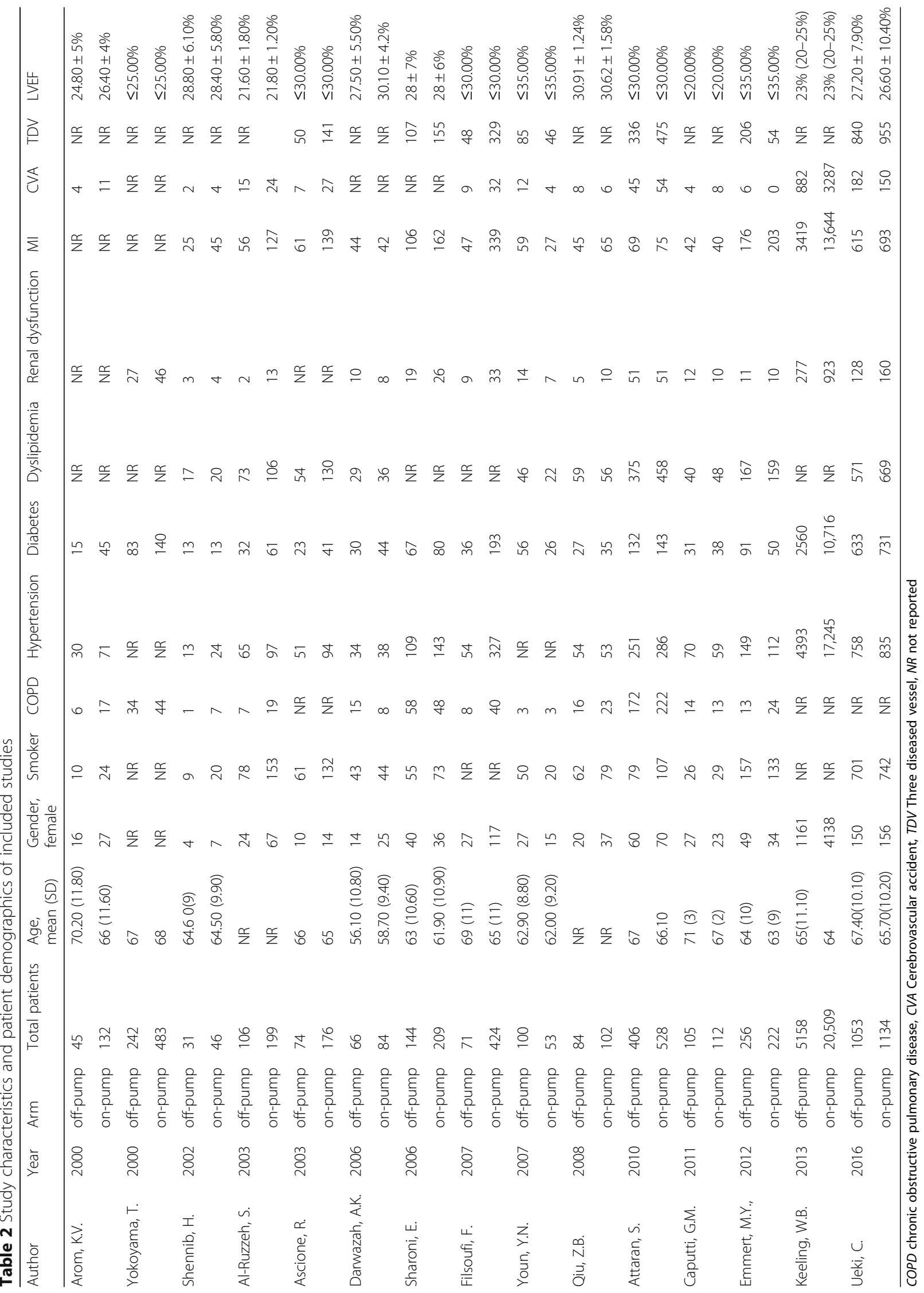




\begin{tabular}{|c|c|c|c|c|c|c|c|c|c|}
\hline \multirow[b]{2}{*}{ Study } & \multicolumn{2}{|c|}{ off-pump } & \multicolumn{2}{|c|}{ on-pump } & \multirow{2}{*}{\multicolumn{2}{|c|}{ off-pump vs on-pump }} & \multirow[b]{2}{*}{ OR } & \multirow[b]{2}{*}{$95 \%-\mathrm{Cl}$} & \multirow[b]{2}{*}{ Weight } \\
\hline & Events & Total & Events & Total & & & & & \\
\hline Arom, K.V.2000 & 2 & 45 & 10 & 132 & & - & 0.57 & {$[0.12 ; 2.69]$} & $2.7 \%$ \\
\hline Yokoyama, T.2000 & 0 & 13 & 1 & 26 & & & 0.63 & {$[0.02 ; 16.53]$} & $0.7 \%$ \\
\hline Shennib, H.2002 & 1 & 31 & 5 & 46 & & - & 0.27 & {$[0.03 ; 2.46]$} & $1.4 \%$ \\
\hline Al-Ruzzeh, S.2003 & 7 & 106 & 28 & 199 & $+\vdots$ & & 0.43 & {$[0.18 ; 1.02]$} & $7.3 \%$ \\
\hline Ascione, R.2003 & 5 & 74 & 5 & 176 & $=$ & $\longrightarrow$ & 2.48 & {$[0.70 ; 8.83]$} & $3.9 \%$ \\
\hline Darwazah, A.K.2006 & 4 & 66 & 9 & 84 & $\pi:$ & - & 0.54 & {$[0.16 ; 1.83]$} & $4.1 \%$ \\
\hline Sharoni, E.2006 & 5 & 144 & 4 & 209 & $\vdots$ & T & 1.84 & {$[0.49 ; 6.99]$} & $3.6 \%$ \\
\hline Filsoufi, F.2007 & 2 & 71 & 16 & 424 & & & 0.74 & {$[0.17 ; 3.29]$} & $2.9 \%$ \\
\hline Youn, Y.N.2007 & 3 & 100 & 2 & 53 & & & 0.79 & {$[0.13 ; 4.87]$} & $2.0 \%$ \\
\hline Qiu, Z.B.2008 & 4 & 84 & 6 & 102 & 7 & . & 0.80 & {$[0.22 ; 2.93]$} & $3.7 \%$ \\
\hline Attaran, S.2010 & 23 & 406 & 41 & 528 & 7 & & 0.71 & {$[0.42 ; 1.21]$} & $13.8 \%$ \\
\hline Caputti, G.M.2011 & 4 & 105 & 14 & 112 & 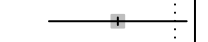 & & 0.28 & {$[0.09 ; 0.87]$} & $4.6 \%$ \\
\hline Emmert, M.Y.,2012 & 6 & 256 & 10 & 222 & r: & - & 0.51 & {$[0.18 ; 1.42]$} & $5.5 \%$ \\
\hline Keeling, W.B.2013 & 158 & 5158 & 629 & 20509 & & & 1.00 & {$[0.84 ; 1.19]$} & $26.3 \%$ \\
\hline Ueki, C.2016 & 36 & 1053 & 67 & 1134 & $\div$ & & 0.56 & {$[0.37 ; 0.85]$} & $17.4 \%$ \\
\hline \multirow{2}{*}{$\begin{array}{l}\text { Random effects model } \\
\text { Heterogeneity: } I^{2}=31 \%, \tau^{2}\end{array}$} & \multicolumn{2}{|c|}{7712} & & 23956 & $\diamond$ & & \multirow{2}{*}{\multicolumn{2}{|c|}{$0.72[0.55 ; 0.94]$}} & $100.0 \%$ \\
\hline & $=0.0631$ & $p=0$ & & & 01 & 10 & & & \\
\hline \multicolumn{7}{|c|}{ Forest plot of 30-day mortality } & & & \\
\hline
\end{tabular}

Secondary outcomes

Off-pump was associated with less stroke (OR, 0.69; 95\% CI, 0.55-0.86; $P=0.00$ ), MI (OR, 0.71;95\% CI, 0.53-0.96; $P=0.02)$, renal failure $(\mathrm{OR}, 0.71 ; 95 \% \mathrm{CI}, 0.55-0.93 ; P=$ $0.01)$, the pulmonary complication $(\mathrm{OR}, 0.68$; $95 \% \mathrm{CI}, 0.52-$ $0.90 ; P=0.01)$, infection $(\mathrm{OR}, 0.67 ; 95 \% \mathrm{CI}, 0.49-0.91 ; P=$
0.00 ), postoperative transfusion $(\mathrm{OR}, 0.25 ; 95 \% \mathrm{CI}, 0.08$ $0.84 ; P=0.02)$, reoperation for bleeding $(\mathrm{OR}, 0.56 ; 95 \% \mathrm{CI}$, $0.41-0.75 ; P=0.00$ ) respectively. However, there was no significant difference in terms of AF (OR, 0.95; 95\% CI, 0.78$1.41 ; P=0.56)$ and neurological dysfunction (OR, $0.84 ; 95 \%$ CI, 0.49-1.57; $P=0.65$ ) (Figs. 3, 4, 5, 6, 7, 8, 9, 10, 11).

\begin{tabular}{|c|c|c|c|c|c|c|c|c|c|}
\hline \multirow{3}{*}{$\begin{array}{l}\text { Study } \\
\text { Arom, K.V.2000 }\end{array}$} & \multirow{2}{*}{\multicolumn{2}{|c|}{$\begin{array}{r}\text { off-pump } \\
\text { Events Total }\end{array}$}} & \multicolumn{2}{|c|}{ on-pump } & \multirow{2}{*}{\multicolumn{2}{|c|}{ off-pump vs on-pump }} & \multirow[b]{2}{*}{ OR } & \multirow[b]{2}{*}{$95 \%-\mathrm{Cl}$} & \multirow[b]{2}{*}{ Weight } \\
\hline & & & Events & Total & & & & & \\
\hline & 0 & 45 & 2 & 132 & & & 0.57 & {$[0.03 ; 12.17]$} & $0.5 \%$ \\
\hline Ascione, R.2003 & 1 & 74 & 4 & 176 & & & 0.59 & {$[0.06 ; 5.36]$} & $1.1 \%$ \\
\hline Goldstein, D.J.2003 & 1 & 100 & 0 & 110 & & & 3.33 & {$[0.13 ; 82.72]$} & $0.5 \%$ \\
\hline Darwazah, A.K.2006 & 0 & 66 & 1 & 84 & & & 0.42 & {$[0.02 ; 10.44]$} & $0.5 \%$ \\
\hline Filsoufi, F.2007 & 1 & 71 & 9 & 424 & & & 0.66 & {$[0.08 ; 5.28]$} & $1.2 \%$ \\
\hline Youn, Y.N.2007 & 1 & 100 & 2 & 53 & & - & 0.26 & {$[0.02 ; 2.91]$} & $0.9 \%$ \\
\hline Qiu, Z.B.2008 & 1 & 84 & 2 & 102 & & & 0.60 & {$[0.05 ; 6.76]$} & $0.9 \%$ \\
\hline Attaran, S.2010 & 3 & 406 & 13 & 528 & & & 0.29 & {$[0.08 ; 1.04]$} & $3.2 \%$ \\
\hline Caputti, G.M.2011 & 1 & 105 & 3 & 112 & & & 0.35 & {$[0.04 ; 3.41]$} & $1.0 \%$ \\
\hline Keeling, W.B.2013 & 68 & 5158 & 394 & 20509 & + & & 0.68 & {$[0.53 ; 0.88]$} & $76.3 \%$ \\
\hline Ueki, C.2016 & 20 & 1053 & 23 & 1134 & 1 & & 0.94 & {$[0.51 ; 1.71]$} & $14.0 \%$ \\
\hline \multirow{2}{*}{\multicolumn{3}{|c|}{ Heterogeneity: $I^{2}=0 \%, \tau^{2}=0, p=0.91$}} & & 23364 & $\Delta$ & & \multirow{3}{*}{\multicolumn{2}{|c|}{$0.68[0.55 ; 0.86]$}} & $100.0 \%$ \\
\hline & & & & & 11 & 1 & & & \\
\hline & & & & & 0.1 & & & & \\
\hline \multicolumn{10}{|c|}{ Forest plot of stroke } \\
\hline
\end{tabular}




\begin{tabular}{|c|c|c|c|c|c|c|c|c|}
\hline Study & $\begin{array}{l}\text { off- } \\
\text { Events }\end{array}$ & $\begin{array}{l}\text { pump } \\
\text { Total }\end{array}$ & $\begin{array}{l}\text { on-p } \\
\text { gents }\end{array}$ & $\begin{array}{c}\text { pump } \\
\text { Total }\end{array}$ & off-pump vs on-pump & OR & $95 \%-\mathrm{Cl}$ & Weight \\
\hline Arom, K.V.2000 & 2 & 45 & 3 & 132 & \begin{tabular}{l|l}
$\vdots$ & 1 \\
& 1
\end{tabular} & 2.00 & {$[0.32 ; 12.37]$} & $4.5 \%$ \\
\hline Shennib, H.2002 & 1 & 31 & 5 & 46 & $\begin{array}{lll}1 & \vdots & \\
\end{array}$ & 0.27 & {$[0.03 ; 2.46]$} & $3.3 \%$ \\
\hline Al-Ruzzeh, S.2003 & 30 & 106 & 44 & 199 & $\vdots+$ & 1.39 & {$[0.81 ; 2.38]$} & $16.5 \%$ \\
\hline Goldstein, D.J.2003 & 1 & 100 & 0 & 110 & & 3.33 & {$[0.13 ; 82.72]$} & $1.7 \%$ \\
\hline Darwazah, A.K.2006 & 0 & 66 & 2 & 84 & & 0.25 & {$[0.01 ; 5.26]$} & $1.8 \%$ \\
\hline Filsoufi, F.2007 & 7 & 71 & 45 & 424 & $\begin{array}{l}1 \\
\vdots\end{array}$ & 0.92 & {$[0.40 ; 2.13]$} & $12.1 \%$ \\
\hline Youn, Y.N.2007 & 2 & 100 & 7 & 53 & 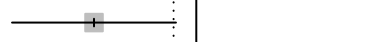 & 0.13 & {$[0.03 ; 0.67]$} & $5.4 \%$ \\
\hline Qiu, Z.B.2008 & 11 & 84 & 15 & 102 & 1 & 0.87 & {$[0.38 ; 2.02]$} & $12.1 \%$ \\
\hline Caputti, G.M.2011 & 9 & 105 & 21 & 112 & +1 & 0.41 & {$[0.18 ; 0.93]$} & $12.2 \%$ \\
\hline Emmert, M.Y.,2012 & 12 & 256 & 26 & 222 & +1 & 0.37 & {$[0.18 ; 0.75]$} & $13.9 \%$ \\
\hline Ueki, C.2016 & 20 & 1053 & 39 & 1134 & $\div$ & 0.54 & {$[0.31 ; 0.94]$} & $16.4 \%$ \\
\hline \multirow{3}{*}{\multicolumn{3}{|c|}{$\begin{array}{l}\text { Random effects model } \\
\text { Heterogeneity: } I^{2}=50 \%, \tau^{2}=0.2171, p=0 .\end{array}$}} & & 2618 & $\dot{0}$ & \multirow{3}{*}{\multicolumn{3}{|c|}{$0.64[0.42 ; 0.99] 100.0 \%$}} \\
\hline & & & & & $\Gamma_{1} \mid 1$ & & & \\
\hline & & & & & $0.1 \quad 0.512$ & & & \\
\hline \multicolumn{9}{|c|}{ Forest plot of the pulmonary complications } \\
\hline
\end{tabular}

\section{Discussions}

This study showed that off-pump CABG can be performed with better operative mortality than on-pump CABG among patients with severe LVD in our metaanalysis of contemporary observational clinical studies involving a large cohort of patients. OPCAB were also demonstrated that the rate of stroke, myocardial infarction, renal failure, pulmonary complication, infection, postoperative transfusion and reoperation for bleeding have better advantage than ONCAB.

The results of the present study are consistent with large individual studies included in the current metaanalysis. Kunadian et.al found that CABG can be performed with acceptable operative mortality and 5-year

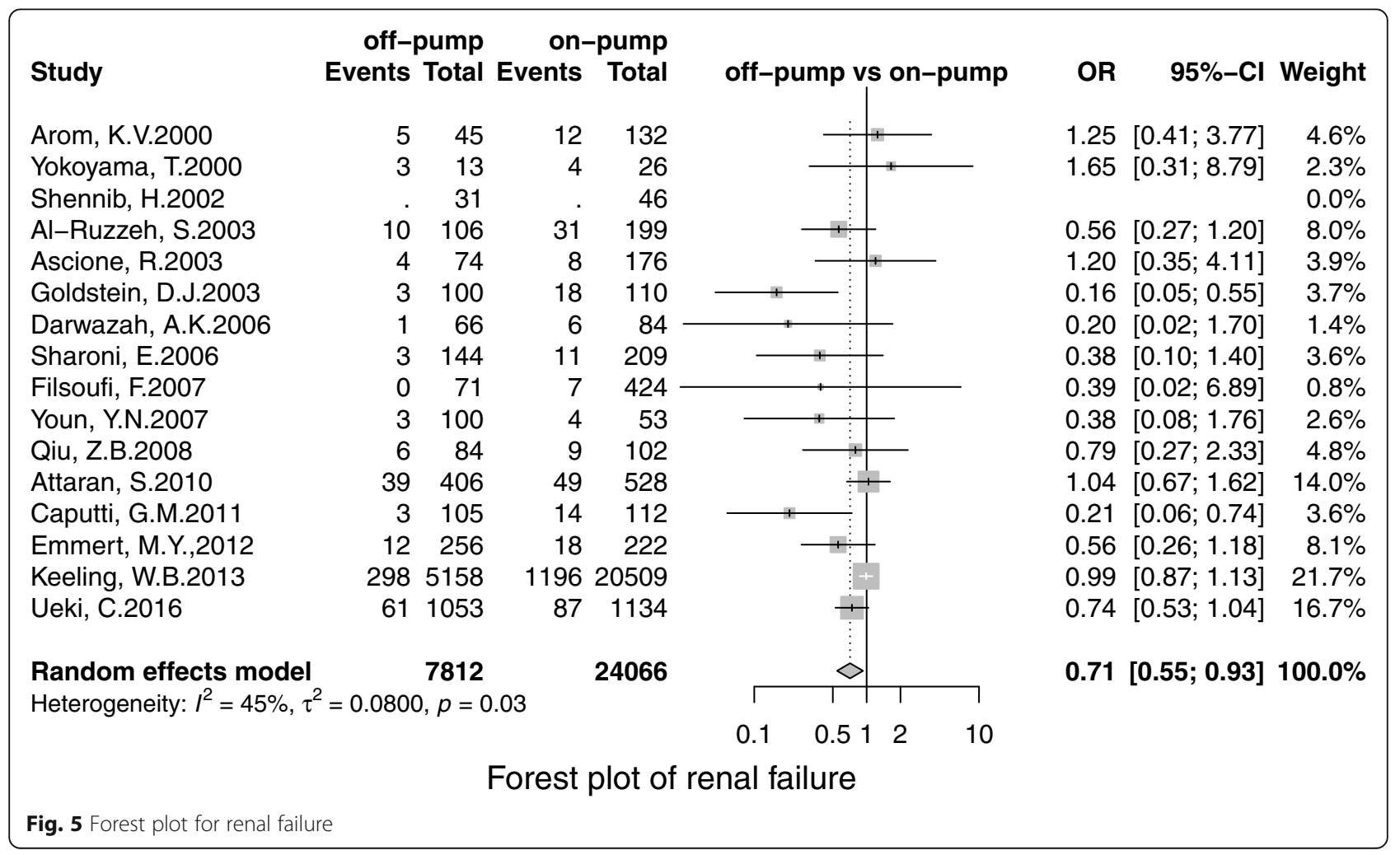




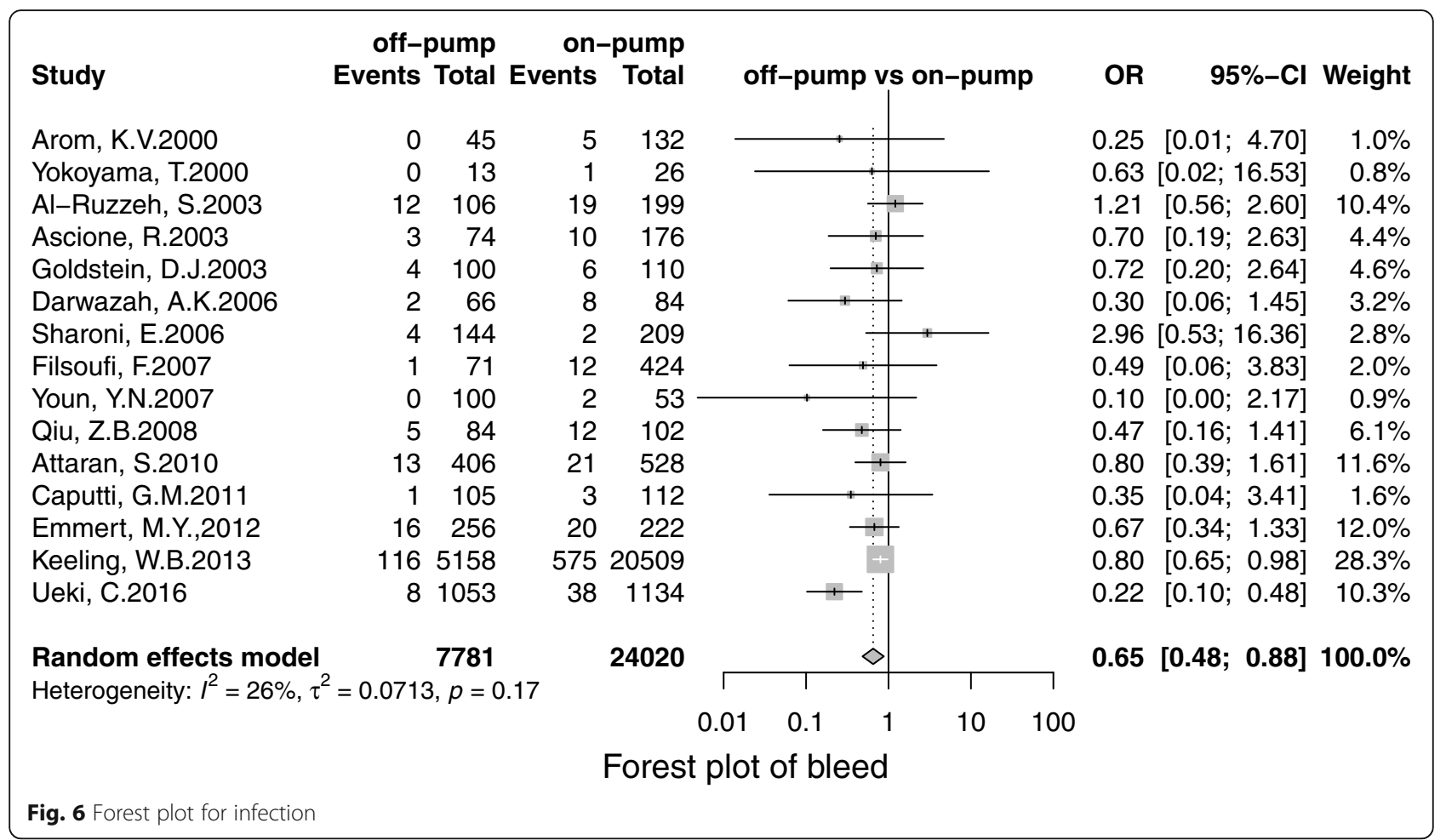

actuarial survival in patients with severe LV dysfunction in the meta-analysis [26]. The Japan Adult Cardiovascular Surgery Database registry of 918 patients with low EF (less than 0.30 ) reported an operative mortality of $3.30 \%$ with off-pump CABG than on-pump CABG (6.10\%) [20]. Keeling et al. in the series of 25,667 patients demonstrated that off-pump CABG compared with on-pump CABG was associated with superior predicted mortality risk $(2.30 \%$ vs $2.10 \%, P=0.0001)$ and Major adverse cardiac events (MACE) $(4.40 \%$ vs $5.30 \%, P=0.01)$ including stroke, MI and atrial fibrillation [17]. Likewise, in a series of 217 patients with $\mathrm{EF} \leq 20 \%$, Capptti et al. demonstrated the operative mortality of $12.50 \%$ in the cardiopulmonary bypass group and $3.80 \%$ in the off-pump group [27].
The less release of inflammatory mediators, cardioplegia, hypothermia, well blood supply for the subendocardium and minimally invasive procedure without cross-clamping, cardiologic arrest and improve flow in IMA grafts make the off-pump CABG an almost-ideal technique for surgery [28-32]. Compared with off-pump CABG, on-pump CABG also has the additional advantage of complete revascularization, hemodynamic deterioration and repeated surgical interventions [30]. Off-pump CABG was also associated with a significantly lower incidence of renal failure, stroke, myocardial infarction, pulmonary complications, postoperative transfusion, infection in this high-risk cohort. A recent large-scale clinical trial study by Garg demonstrated that off-pump reduced the risk of acute postoperative kidney than on-pump CABG, but no

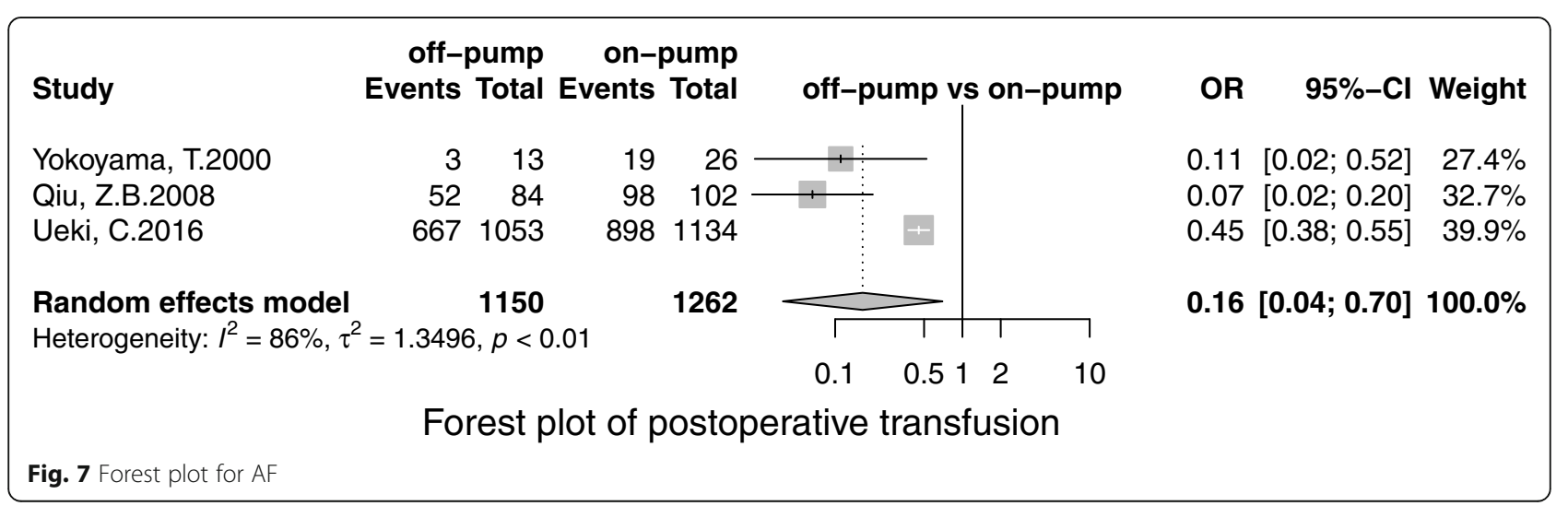




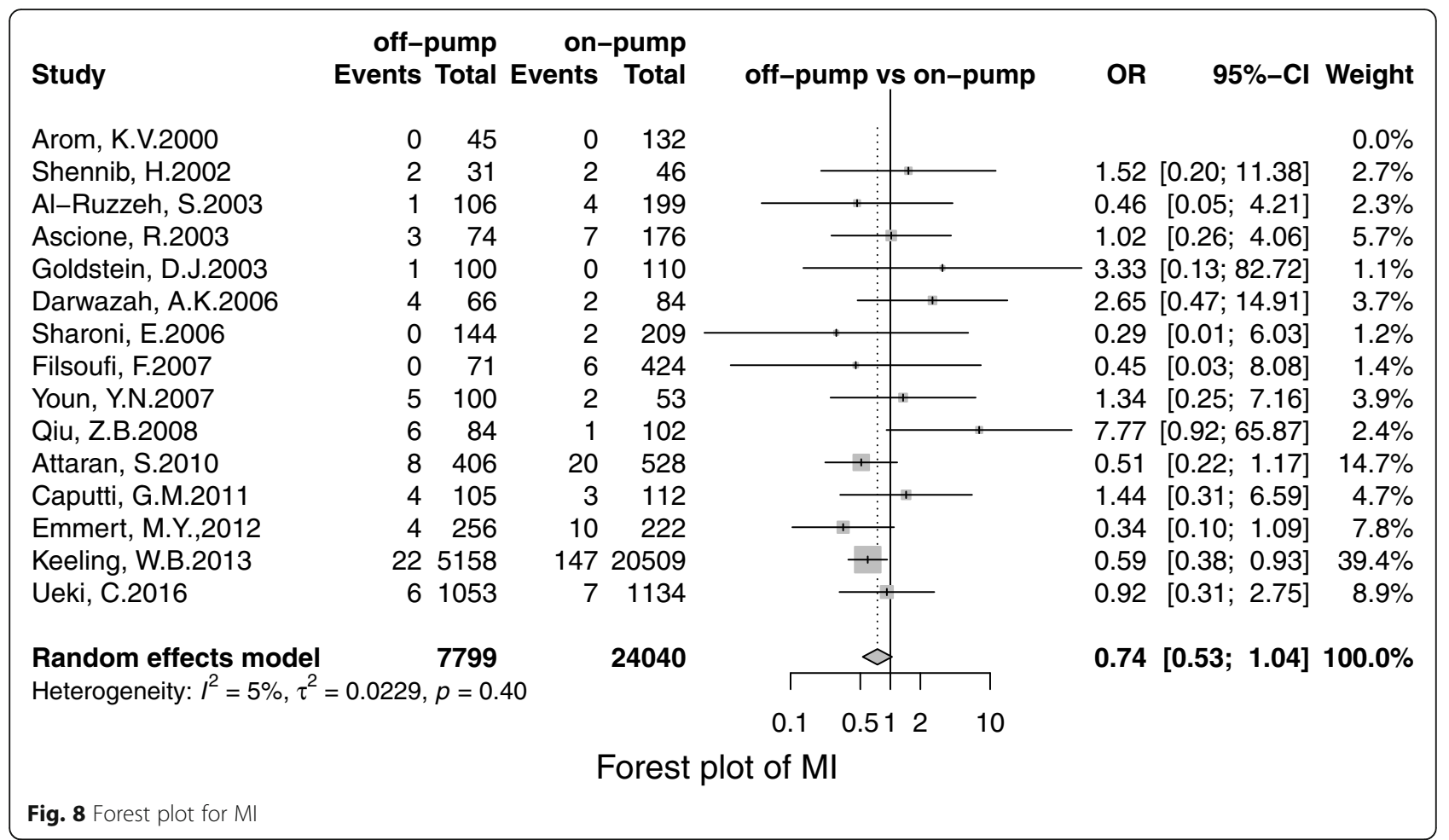

evidence shows better-preserved kidney function at 1 year follow Avoidance of transfusion and eliminate extracorporeal circulation is thought to be the main reasons for the lower incidence of renal failure [28, 33, 34]. Numerous studies have reported the association of off-pump CABG with the reduced requirement of transfusion in patients with left ventricular dysfunction [35]. However, No improvement in neurocognitive outcomes after off-pump versus on-pump coronary revascularization [36].

The off-pump CABG involves less hypercoagulable state and thromboembolic events, thus reducing micro emboli, activation of the coagulation and inflammatory cascades [37]. Yeatman et al. reported that the patients undergoing either off-pump CABG or on-pump CABG for LVD show that off-pump CABG displayed lower requirements for inotropes, less transfusion requirement, and a slightly shorter hospital stay, but at the price of less complete revascularization [38]. Sawada et al. found that coronary revascularization improves long-term survival and a wide range of viability in 274 patients with ischemic left ventricular dysfunction [39]. Jarral et al. found that the preoperative LVEF had adverse effect on

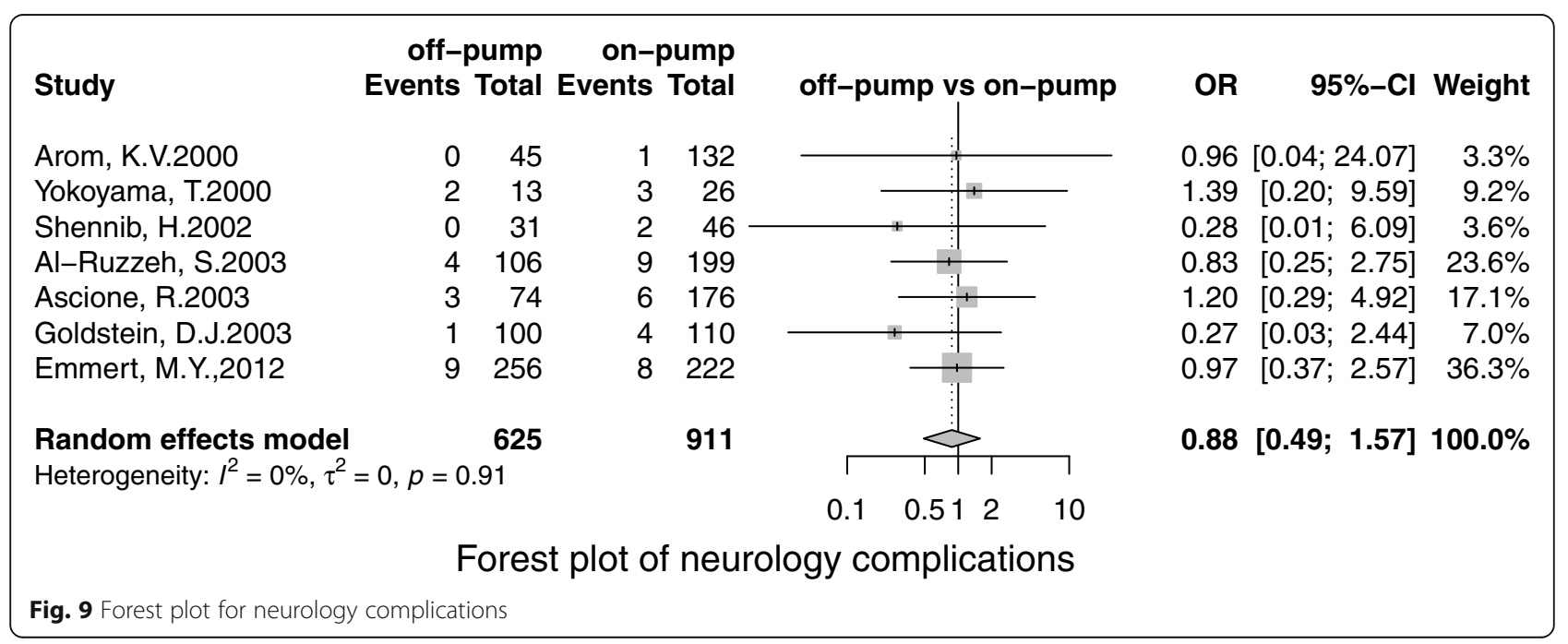




\begin{tabular}{|c|c|c|c|c|c|c|c|c|c|c|c|}
\hline \multirow{2}{*}{$\begin{array}{l}\text { Study } \\
\text { Arom, K.V.2000 }\end{array}$} & \multicolumn{4}{|c|}{$\begin{array}{c}\text { off-pump on-pump } \\
\text { Events Total Events Total }\end{array}$} & \multicolumn{4}{|c|}{ off-pump vs on-pump } & \multirow[t]{2}{*}{ OR } & \multirow[t]{2}{*}{$95 \%-\mathrm{Cl}$} & \multirow{2}{*}{$\begin{array}{r}\text { Weight } \\
0.0 \%\end{array}$} \\
\hline & 0 & 45 & 0 & 132 & & & & & & & \\
\hline Al-Ruzzeh, S.2003 & 9 & 106 & 24 & 199 & & 1 & - & & 0.68 & {$[0.30 ; 1.51]$} & $15.2 \%$ \\
\hline Ascione, R.2003 & 5 & 74 & 20 & 176 & & $1,-1$ & — & & 0.57 & {$[0.20 ; 1.57]$} & $10.6 \%$ \\
\hline Darwazah, A.K.2006 & 4 & 66 & 6 & 84 & & & & & 0.84 & {$[0.23 ; 3.10]$} & $6.9 \%$ \\
\hline Sharoni, E.2006 & 1 & 144 & 2 & 209 & & & & & 0.72 & {$[0.07 ; 8.06]$} & $2.2 \%$ \\
\hline Filsoufi, F.2007 & 6 & 71 & 16 & 424 & & & 1 & & 2.35 & {$[0.89 ; 6.23]$} & $11.4 \%$ \\
\hline Qiu, Z.B.2008 & 7 & 84 & 8 & 102 & & & & & 1.07 & {$[0.37 ; 3.08]$} & $9.9 \%$ \\
\hline Attaran, S.2010 & 11 & 406 & & 528 & & 1, & & & 0.46 & {$[0.23 ; 0.93]$} & $18.5 \%$ \\
\hline Ueki, C.2016 & 20 & 1053 & 39 & 1134 & & 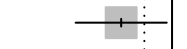 & & & 0.54 & {$[0.31 ; 0.94]$} & $25.3 \%$ \\
\hline \multirow{3}{*}{$\begin{array}{l}\text { Random effects model } \\
\text { Heterogeneity: } I^{2}=22 \%, \tau\end{array}$} & & 2049 & & 2988 & & $\infty$ & & & \multirow{3}{*}{\multicolumn{2}{|c|}{$0.72[0.50 ; 1.04]$}} & $100.0 \%$ \\
\hline & $\tau^{2}=0.0607$ & $p=0$ & & & 1 & & $T$ & $\neg$ & & & \\
\hline & & & & & 0.1 & 0.51 & 2 & 10 & & & \\
\hline \multicolumn{9}{|c|}{ Forest plot of infection } & & & \\
\hline
\end{tabular}

long-term survival of patients with LVD and the longterm survival of patients with severe LVD was significantly lower than those with mild to moderate LVD [40]. But Reid et al. demonstrated that the clinical outcome is improved by surgical revascularization can reduce organ dysfunction which also can improve survival [41].

Many preoperative factors were found to be associated with mortality in CABG with LVD including female sex, increasing older age, diabetes, and peripheral vascular disease as predictors [42, 43]. Margo et al. found that the age ( $>70$ years) and female influences on the needs, concerns, and strategies of CABG caregivers. The effect of CABG on all-cause mortality tended to diminish with increasing age through a more significant burden of comorbidities, which in turn lead to a higher risk of postoperative complications and non-cardiovascular deaths [43]. Both short-and long-term cardiac outcomes of odd-pump CABG are not influenced by age at the operation which prevents the potential complications that can occur in patients undergoing CABG with CPB [44]. The surgeon experience also the essential factors for the

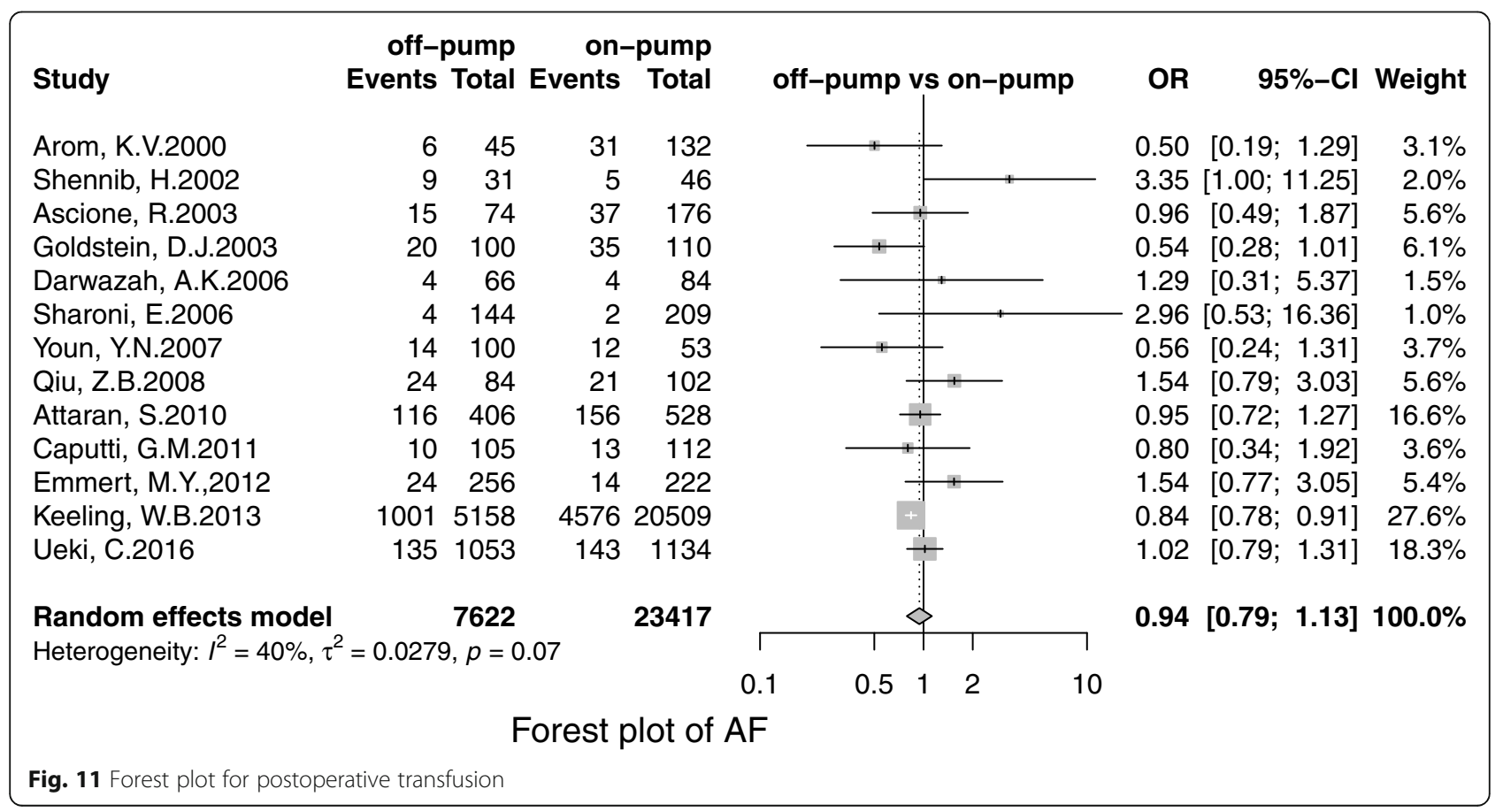


clinical outcome of CABG which improved by surgical technique, surgeon volume, and hospital volume, changed surgical training [45-48].

\section{Limitations}

There are many limitations should be acknowledged. Firstly, the number of patients, the inclusion and the exclusion criteria, the type of surgery, the indication for CABG, methods for the assessment of LV function and the definition of the severe LVD varied across the studies, and the EF has represented a systolic function which cannot be demonstrated left ventricular dimension and diastolic function. Secondly, the surgeon's volume index and institutional volume index also were not significantly associated with the clinical outcome because the learning curve of off-pump CABG is longer than onpump CABG. Finally, the present study remains subject to the inherent caveats of a meta-analysis including publication bias, however, in-depth statistical analysis was performed to account for these limitations. In future, the more RCT studies need to studies the clinical outcome of OPCAB and ONCAB.

\section{Conclusions}

The published evidence on the clinical effect of the use the off-pump CABG for LVD is mainly derived singlecenter observational studies from the institutions. The key finding is that the use of off-pump CABG is associated with a reduction in mortality and this finding also provide better implications for clinicians and policymakers .

\section{Supplementary information}

Supplementary information accompanies this paper at https://doi.org/10. 1186/s13019-020-01115-0.

Additional file 1. Search strategy.

Additional file 2: Figure S1. a-1b 30-day mortality: (a) Funnel plot with Egger test results and (b) Leave-one-out analysis.

\section{Abbreviations}

LVD: Left ventricular dysfunction; CABG: Coronary artery bypass grafting; CNS: Central nervous system complications; ICU LOS: The length of stay of an intensive care unit; CPB: Cardiopulmonary bypass; MED: Medical therapy; AKI: Acute kidney disease; CKD: Chronic kidney disease

\section{Acknowledgements}

Not applicable.

\section{Patient and public involvement}

This is no patient and public Involvement.

\section{Authors' contributions}

Conceived and designed the experiments: ZYG MX CLS ZZ FW. Performed the experiments: ZYG XQG YQL. Analyzed the data: ZYG XQG KYG YQL JL WJZ MX CLS. Contributed reagents/ materials/analysis tools: ZYG XQG KYG YQL JL WJZ MX CLS. Wrote the paper: ZYG XQG KYG YQL JL WJZ MX CLS ZZ. The author(s) read and approved the final manuscript.

\section{Funding}

This work was partly supported by the National Natural Science Foundation of China (Grant No. 11902149). This work is also sponsored by China Postdoctoral Science Foundation Grant (Grant No. 2018 M640030) and Key clinical project of Peking University Third Hospital(Y75510-04)

\section{Availability of data and materials}

Not applicable.

\section{Ethics approval and consent to participate}

As a meta-analysis, no patients involved in the recruitment to and conduct of the study and there also no results be disseminated to study participants. The inclusion criteria and exclusion criteria were used to screen inclusion studies, and leave-out tests were used to analyze the impact of each study on the overall structure.

\section{Consent for publication}

Not applicable.

\section{Competing interests}

There is no found and interest in the papers

\section{Author details}

${ }^{1}$ Department of Cardiology surgery, Peking University Third Hospital, 49 North Garden Rd., Haidian District, Beijing 100191, China. ${ }^{2}$ Peking University, Beijing 100871, China. ${ }^{3}$ Beijing University of Technology, Beijing 100124 , China. ${ }^{4}$ Department of Cardiology, Peking University Third Hospital, NHC Key Laboratory of Cardiovascular Molecular Biology and Regulatory Peptides, Beijing 100191, China. ${ }^{5}$ Shanghai East Hospital, Tongji University, 150 Jimo Rd., Pudong District, Shanghai 100124, China. ${ }^{6}$ Department of Orthopedics, Peking University Third Hospital, 49 North Garden Rd., Haidian District, Beijing 100191, China.

Received: 19 December 2019 Accepted: 27 April 2020

Published online: 11 May 2020

\section{References}

1. Kowalewski M, et al. Off-pump coronary artery bypass grafting improves short-term outcomes in high-risk patients compared with on-pump coronary artery bypass grafting: Meta-analysis. J Thorac Cardiovasc Surg. 2016;151(1):60-77 e1-58.

2. Smart NA, Dieberg G, King N. Long-term outcomes of on-versus off-pump coronary artery bypass grafting. J Am Coll Cardiol. 2018;71(9):983-91.

3. Topkara VK, et al. Coronary artery bypass grafting in patients with low ejection fraction. Circulation. 2005;112(9 Suppl):I344-50.

4. Luchi RJ, Scott SM, Deupree RH. Comparison of medical and surgical treatment for unstable angina pectoris. Results of a veterans administration cooperative study. N Engl J Med. 1987:316(16):977-84.

5. Filsoufi F, et al. Results and predictors of early and late outcome of coronary artery bypass grafting in patients with severely depressed left ventricular function. Ann Thorac Surg. 2007;84(3):808-16.

6. Ferguson TB Jr, et al. A decade of change--risk profiles and outcomes for isolated coronary artery bypass grafting procedures, 1990-1999: a report from the STS National Database Committee and the Duke Clinical Research Institute. Society of Thoracic Surgeons. Ann Thorac Surg. 2002;73(2):480-9 discussion 489-90.

7. Jarral OA, Saso S, Athanasiou T. Off-pump coronary artery bypass in patients with left ventricular dysfunction: a meta-analysis. Ann Thorac Surg. 2011; 92(5):1686-94.

8. Viechtbauer W. Conducting Meta-analyses in R with the metafor package. J Stat Softw. 2010;36(3):1-48

9. Higgins JP, Green S. Cochrane handbook for systematic reviews of interventions: Cochrane book series; 2008

10. Higgins JP, et al. Measuring inconsistency in meta-analyses. BMJ. 2003, 327(7414):557-60.

11. Al-Ruzzeh S, et al. Is the use of cardiopulmonary bypass for multivessel coronary artery bypass surgery an independent predictor of operative mortality in patients with ischemic left ventricular dysfunction? Ann Thorac Surg. 2003;76(2):444-51 discussion 451-2.

12. Arom $\mathrm{KV}$, et al. Is low ejection fraction safe for off-pump coronary bypass operation? Ann Thorac Surg. 2000;70(3):1021-5. 
13. Ascione R, et al. Early and midterm clinical outcome in patients with severe left ventricular dysfunction undergoing coronary artery surgery. Ann Thorac Surg. 2003;76(3):793-9.

14. Attaran S, et al. Does off-pump coronary artery revascularization improve the long-term survival in patients with ventricular dysfunction? Interact Cardiovasc Thorac Surg. 2010;11(4):442-6.

15. Darwazah AK, et al. Myocardial revascularization in patients with low ejection fraction $<$ or $=35 \%$ : effect of pump technique on early morbidity and mortality. J Card Surg. 2006;21(1):22-7.

16. Emmert MY, et al. Off-pump surgery is not a contraindication for patients with a severely decreased ejection fraction. Heart Surgery Forum. 2011;14(5): 302-6.

17. Keeling WB, et al. Off-pump and on-pump coronary revascularization in patients with low ejection fraction: a report from the Society of Thoracic Surgeons National Database. Ann Thorac Surg. 2013;96(1):83-8.

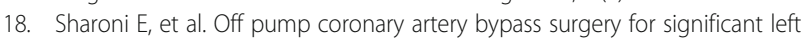
ventricular dysfunction: safety, feasibility, and trends in methodology over time--an early experience. Heart. 2006;92(4):499-502.

19. Shennib H, et al. Surgical revascularization in patients with poor left ventricular function: on- or off-pump? Ann Thorac Surg. 2002;74(4):S1344-7.

20. Ueki $C$, et al. Off-pump versus on-pump coronary artery bypass grafting in patients with left ventricular dysfunction. J Thorac Cardiovasc Surg. 2016; 151(4):1092-8.

21. Yokoyama T, et al. Off-pump versus on-pump coronary bypass in high-risk subgroups. Ann Thorac Surg. 2000;70(5):1546-50.

22. Caputti GM, et al. Off-pump coronary artery bypass surgery in selected patients is superior to the conventional approach for patients with severely depressed left ventricular function. Clinics (Sao Paulo). 2011;66(12):2049-53.

23. Goldstein DJ, et al. Multivessel off-pump revascularization in patients with severe left ventricular dysfunction. Eur J Cardiothorac Surg. 2003;24(1):72-80.

24. Youn YN, et al. Early and mid-term impacts of cardiopulmonary bypass on coronary artery bypass grafting in patients with poor left ventricular dysfunction: a propensity score analysis. Circ J. 2007;71(9):1387-94.

25. Qiu ZB, et al. Is the use of cardiopulmonary bypass for isolated coronary artery bypass an independent predictor of mortality and morbidity in patients with severe left ventricular dysfunction? Chin Med J. 2008;121(23): 2397-402

26. Kunadian V, Zaman A, Qiu W. Revascularization among patients with severe left ventricular dysfunction: a meta-analysis of observational studies. Eur J Heart Fail. 2011;13(7):773-84.

27. Guido Marco C, et al. Off-pump coronary artery bypass surgery in selected patients is superior to the conventional approach for patients with severely depressed left ventricular function. Clinics. 2011;66(12):2049-53.

28. Ardawan Julian $\mathrm{R}$, et al. On-pump beating heart versus off-pump coronary artery bypass surgery-evidence of pump-induced myocardial injury. Eur $J$ Cardiothorac Surg. 2005;27(6):1057.

29. Oner $\mathrm{G}$, et al. On-pump/beating-heart myocardial protection for isolated or combined coronary artery bypass grafting in patients with severe left ventricle dysfunction: assessment of myocardial function and clinical outcome. Heart Surg Forum. 2005;8(3):E178.

30. Santiago $\mathrm{G}$, et al. Outcomes after complete versus incomplete revascularization of patients with multivessel coronary artery disease: a meta-analysis of 89,883 patients enrolled in randomized clinical trials and observational studies. J Am Coll Cardiol. 2013;62(16):1421-31.

31. Busheng $Z$, et al. Comparison of graft patency between off-pump and onpump coronary artery bypass grafting: an updated meta-analysis. Ann Thorac Surg. 2014;97(4):1335-41.

32. Benedetto $U$, et al. Off-pump versus on-pump coronary artery bypass grafting: insights from the arterial revascularization trial. J Thorac Cardiovasc Surg. 2018;155(4):1545-53 e7.

33. Holzmann MJ, et al. Renal dysfunction and long-term risk of ischemic and hemorrhagic stroke following coronary artery bypass grafting. Int J Cardiol. 2013;168(2):1137-42.

34. Seung Seok $\mathrm{H}$, et al. Effects of acute kidney injury and chronic kidney disease on long-term mortality after coronary artery bypass grafting. Am Heart J. 2015;169(3):419-25.

35. Gaetano P, et al. Preoperative predicted risk does not fully explain the association between red blood cell transfusion and mortality in coronary artery bypass grafting. J Thorac Cardiovasc Surg. 2012;143(1):178-85.

36. Marasco SF, Sharwood LN, Abrarnson MJ. No improvement in neurocognitive outcomes after off-pump versus on-pump coronary revascularisation: a meta-analysis. Eur J Cardiothorac Surg. 2008;33(6):96170.

37. Stamou SC, et al. Stroke after coronary artery bypass: incidence, predictors, and clinical outcome. Stroke. 2001;32(7):1508-13.

38. Yeatman $M$, et al. Off-pump coronary artery bypass surgery for critical left main stem disease: safety, efficacy and outcome. Eur J Cardiothorac Surg. 2001;19(3):239-44.

39. Sawada SG, et al. Effect of revascularization on long-term survival in patients with ischemic left ventricular dysfunction and a wide range of viability. Am J Cardiol. 2010;106(2):187-92.

40. Jarral OA, Saso S, Athanasiou T. Does off-pump coronary artery bypass surgery have a beneficial effect on mortality in patients with left ventricular dysfunction? Interact Cardiovasc Thorac Surg. 2012;14(6):856-64.

41. Reid C, et al. Clinical characteristics and mortality of patients with multivessel coronary disease undergoing coronary artery bypass grafting compared with percutaneous coronary intervention: a comparison between 2 multi-Centre registries. Heart Lung Circ. 2010;19(8):503.

42. Vasim F, et al. Response to letter regarding article, "quantification of incomplete revascularization and its association with five-year mortality in the synergy between percutaneous coronary intervention with Taxus and cardiac surgery (SYNTAX) trial: validation of the re". Circ Cardiovasc Imaging. 2013;128(2):141-51.

43. Kang $\mathrm{SH}$, et al. Comparison of outcomes of coronary artery bypass grafting versus drug-eluting stent implantation in patients with severe left ventricular dysfunction. Am J Cardiol. 2017;120(1):69-74.

44. Ohira S, et al. Does age at operation influence the short- and long-term outcomes of off-pump coronary artery bypass grafting? Circ J. 2015;79(10): 2177-85.

45. Birkmeyer JD, et al. Surgeon volume and operative mortality in the United States. N Engl J Med. 2003;349(22):2117-27.

46. Bakaeen FG, et al. Does the level of experience of residents affect outcomes of coronary artery bypass surgery? Ann Thorac Surg. 2009;87(4):1127-34.

47. Chowdhury MM, Dagash $\mathrm{H}$, Pierro A. A systematic review of the impact of volume of surgery and specialization on patient outcome. Br J Surg. 2007; 94(2):145-61.

48. Mahiben $M$, et al. Surgical learning curves and operative efficiency: a crossspecialty observational study. BMJ Open. 2015;5(3):e006679.

\section{Publisher's Note}

Springer Nature remains neutral with regard to jurisdictional claims in published maps and institutional affiliations.

Ready to submit your research? Choose BMC and benefit from:

- fast, convenient online submission

- thorough peer review by experienced researchers in your field

- rapid publication on acceptance

- support for research data, including large and complex data types

- gold Open Access which fosters wider collaboration and increased citations

- maximum visibility for your research: over $100 \mathrm{M}$ website views per year

At $\mathrm{BMC}$, research is always in progress.

Learn more biomedcentral.com/submission 